\title{
Consideraciones sociales en el diseño y planificación de parques urbanos
}

\author{
RAMiro Flores-XolocotzI \\ Manuel de Jesús GonZÁlez-Guillén*
}

Resumen

Los parques urbanos han sido creados desde tiempos históricos con la finalidad de proporcionar diversos servicios destinados a beneficiar a determinados grupos sociales. Actualmente, el concepto de parques públicos incluye principios de sustentabilidad ecológica, económica y social, es debido a ello que se permite considerarlos como espacios incluyentes y con usos recreativos diversos. Sin embargo, a través de un análisis de estudios de caso en mujeres, etnias, razas, homosexuales y personas con discapacidades o con necesidades especiales, este trabajo expone que los parques actuales distan de ser incluyentes. Esta deficiencia podría repercutir negativamente en la calidad y uso de los mismos. En este documento se sugieren estrategias y recomendaciones que permiten la creación de programas de asignación, diseño y manejo de parques bajo una perspectiva de inclusión y equidad considerando demanda social recreativa y participación ciudadana.

Palabras clave: equidad, espacios verdes, inclusión, participación ciudadana, recreación.

\begin{abstract}
Since historical times, urban parks have been created to provide some services for the benefit of certain social groups. Nowadays, the concept of public park includes some principles of ecological, economical and social sustainability and thus it is possible to consider them as places of inclusion and with a diversity of recreational purposes. Nonetheless, through the analysis of some case studies with women, ethnic groups, racial groups, homosexuals, disabled people or people with special needs, this paper proposes that today's parks are far from being inclusive. This deficiency can have negative effects in the quality and use of the parks themselves. We suggest some strategies and recommendations that allow the creation of programmes for the allocation, design and management of parks under a perspective of inclusion and fairness, by considering the recreational social demand and the citizens' participation.
\end{abstract}

Keywords: fairness, green spaces, inclusion, citizen participation, recreation.

* Colegio de Postgraduados, Campus Montecillo, México. Correos-e: floresxzr@ prodigy.net.mx, manuelg@colpos.mx. 


\section{Introducción}

Según la Comisión Mundial del Medio Ambiente y del Desarrollo (CMMD, 1988), al inicio del siglo xxi prácticamente la mitad de la humanidad habitará en centros urbanos; otras estimaciones establecen que la rápida urbanización de las sociedades humanas permitirá que en el año 2030, más de 60\% de la población mundial viva en ciudades (United Nations, citado en Bolund y Hunhammar, 1999: 193). Sin embargo, diversas ciudades del siglo XXI, especialmente aquéllas ubicadas en naciones emergentes, arrastran históricamente problemas ligados a un crecimiento y desarrollo urbano no planificado que han sido objeto de discusión, al menos desde el inicio de la Revolución Industrial. Esos problemas críticos de planificación urbana resultan en una desigual dotación de bienes y servicios urbanos que restringe la calidad de vida de los habitantes. No obstante esa preocupación histórica de al menos 300 años por el crecimiento y desarrollo de las ciudades, las urbes actuales se caracterizan por tener en común problemas ambientales y sociales como contaminación, déficit de espacios verdes, ${ }^{1}$ inseguridad, desigualdad social y discriminación de grupos sociales dentro de los espacios urbanos.

Por lo anterior, la CMMD (1988) sugirió que los programas y políticas públicas para el desarrollo y bienestar urbanos consideren indicadores de sustentabilidad y estándares de calidad de vida que tomen en cuenta aspectos económicos, ecológicos y sociales. Uno de los indicadores propuestos por la Organización Mundial de la Salud (OMS) y por el Programa de Naciones Unidas para el Medio Ambiente (PNUMA, 2003), es la superficie de áreas verdes urbanas por habitante. Al respecto, actualmente, la oms recomienda un mínimo de $9 \mathrm{~m}^{2}$. También aconseja un diseño de áreas verdes que permita a los citadinos vivir a una distancia de no más de 15 minutos a pie de un espacio verde público (Miller, 1997; Sorensen et al., 1998); consecuentemente, los espacios deberían establecerse entre sí al doble de la distancia mencionada.

Además, considerando principios de sustentabilidad social, se sugiere que los beneficios que proporcionan los espacios verdes públicos se distribuyan equitativamente entre los diferentes grupos sociales que integran la sociedad, y que esos grupos participen de forma activa en los planes de asignación y diseño de áreas verdes urbanas (Speller y Ravenscroft, 2005). Los indicadores y

${ }^{1}$ En este documento, los términos parques públicos, parques urbanos, espacios verdes y áreas verdes se consideran sinónimos. 
sugerencias de los organismos internacionales constituyen un reconocimiento internacional sobre los múltiples beneficios ambientales, sociales y de salud que los parques públicos proporcionan, y que son descritos por Ariane Bedimo-Rung y otros autores (2005).

Por lo anterior, la distribución equitativa de tales beneficios se logrará únicamente si se conciben los espacios verdes (al igual que cualquier espacio público urbano) como sitios que permitan el acceso a los diferentes grupos sociales presentes en las localidades urbanas. Desde esta óptica de acceso a los espacios públicos, y de acuerdo con Lennie Scott-Webber y Anna MarshallBaker (1998: 10), existe equidad cuando los ciudadanos tienen igual oportunidad de interactuar o afectar sus ambientes.

De acuerdo con los anterior, se considera a los parques urbanos como espacios incluyentes y de usos diversos para la población, sin distinción de género, ${ }^{2}$ orientación sexual, razas, discapacidades, posición económica o clase social, y cuyo objetivo principal es incrementar la calidad de vida urbana (Chiesura, 2004).

\section{Planteamiento y objetivos}

Los parques citadinos constituyen parte fundamental del paisaje urbano y se pueden caracterizar como un bien complementario a la dotación de vivienda por los diversos beneficios que proporcionan a todos los grupos sociales que viven en la ciudad. Esta complementariedad puede rastrearse en el tiempo varios siglos atrás. De modo tal que su inclusión actual en los programas de planificación urbana está definida por una serie de sucesos históricos que permiten entender los actuales aspectos de asignación, manejo y administración de espacios verdes urbanos hasta llegar a la actual óptica de sustentabilidad económica, social y ecológica.

Las deficiencias de inclusión social en las áreas verdes citadinas se analizan desde el enfoque de sustentabilidad. Consecuentemente, el objetivo principal en este trabajo es exponer, por medio de un análisis de estudios de caso en mujeres, etnias, razas, homosexuales ${ }^{3}$ y personas con discapacidades de diferentes

\footnotetext{
${ }^{2}$ Como género se entiende lo considerado por Marta Lamas (1998): lo que la sociedad concibe que debe ser propio de un hombre y propio de una mujer tomando como referencia la anatomía respectiva de cada uno y sus funciones reproductivas evidentemente distintas.

${ }^{3}$ El término homosexual se emplea para referirse a hombres que gustan de tener contactos eróticos con otros hombres. De acuerdo con Arturo Sánchez (2002), el
} 
tipos, que los parques distan de ser espacios incluyentes en sus usos. Esa deficiencia podría repercutir negativamente en la calidad y uso de los mismos.

Para alcanzar el objetivo general, el análisis se dividió en tres partes:

a) Se realiza una breve revisión histórica de la asignación de espacios verdes urbanos, lo que permite detectar de manera histórica la exclusión social desde tiempo pasado.

b) Se presenta un análisis de la situación actual de la exclusión y discriminación de los grupos anteriormente mencionados en los espacios verdes urbanos.

c) Se sugieren algunas estrategias y recomendaciones que permitan el diseño y manejo de parques públicos desde una perspectiva de equidad e inclusión social dentro del espacio, además se resaltan las bondades de la participación ciudadana como una forma de lograr programas de asignación, diseño y manejo de espacios verdes incluyentes.

\section{Los parques urbanos y la exclusión social: breve historia}

Hablar de las primeras ciudades surgidas en función del poder político y religioso es remontarse a Mesopotamia, en donde hacia el año 3000 a.C. se encuentra una sociedad neolítica: "los sumerios", que tendían a agruparse en núcleos protourbanos (Nieto, 2000: 2166).

Esos núcleos protourbanos evolucionaron durante los siguientes dos milenios hacia la conformación de las primeras ciudades, como Babilonia, ciudad que evidencia un primer nivel de planificación urbana tendente a proporcionar servicios religiosos, gobierno, vivienda y comercio. Es en esta antiquísima ciudad donde se pueden encontrar algunos de los primeros diseños de vegetación de tipo jardín elaborados para embellecer una ciudad. Esos primeros diseños constituyeron los llamados Jardines Colgantes de Babilonia, creados dentro de los palacios reales durante el periodo del rey Nabucodonosor II, entre los años 604 y 562 a.C.

Aun y cuando esas zonas verdes fueron consideradas parte arquitectónica de las ciudades antiguas, no cobraron auge du-

término incluye a aquellos hombres que se reconocen como gays aceptando su preferencia homosexual, y a hombres que se reconocen como heterosexuales y que gustan también del mismo tipo de contactos eróticos. 
rante los siguientes mil años. Esta relación se observa en un inicio en forma de pequeños jardines privados (Fernow, 1911). Posteriormente, durante la Edad Media también se podían encontrar jardines ubicados en las moradas de la clase gobernante y en espacios dentro de templos religiosos. Esa falta de interés posiblemente esté relacionada con el hecho de que las primeras ciudades eran pequeñas, comparadas con las actuales; además de que los primeros citadinos tenían mayores oportunidades en términos de distancia y tiempo para acudir al campo fuera de la ciudad. Por lo anterior, tipos funcionales y arquitectónicos semejantes a los Jardines Colgantes de Babilonia son los que representaron las primeras zonas verdes citadinas durante una buena parte de la historia urbana.

Posteriormente, en el Renacimiento, las zonas verdes se extienden a espacios abiertos creados para el disfrute de las clases noble y alta; esas zonas generalmente se ubicaron fuera del centro o a las orillas de las ciudades. Sería éste el caso del parque de la Alameda Central en la Ciudad de México, creado en 1593, como lo refiere Ramona Pérez (2003: 1):

La desecación de los cinco lagos del Valle de México dejó atrás la ciudad mítica azteca de Tenochtitlan integrada con agua y vegetación para formar la metrópoli colonial española cuyas plazas y calles no contaban con árboles. Por ello, a finales del siglo XVI se creó al poniente de la capital de la Nueva España, la Alameda Central para brindar belleza a la ciudad y un lugar de recreo de las clases altas.

Hasta ese momento histórico, y considerando el objetivo social de dichos espacios abiertos, no se puede hablar aún de parques públicos tal como se conciben actualmente, ya que esos espacios en Europa y América estaban dirigidos sólo a las clases altas y a la nobleza.

Tres siglos después, la Revolución Industrial, además de generar grandes beneficios, trae consigo enormes problemas sociales y de salud producto de una desorganizada planificación urbana, como lo describe Friedrich Engels (1999) para las ciudades inglesas de principios del siglo XIX. Dicha Revolución se puede considerar como un catalizador que puso en la mesa de discusión de gobernantes y científicos, las formas y estrategias para mejorar las condiciones de vida urbana. Tal situación estimuló el origen y aplicación de diversas ideologías en arquitectura y urbanismo durante los siglos XVIII y XIX, sobresaliendo el racionalismo, el liberalismo, el utilitarismo y el higienismo, entre otras. Ese periodo histórico corresponde a lo que Federico Fernández 
(2000) denomina periodo neoclásico de la arquitectura y el urbanismo, el cual permitió el desarrollo paulatino de nuevos modelos de ciudades. Esos modelos se tradujeron en esquemas de dotación de bienes y servicios como las áreas verdes. Evidencia de ello fue la planeación de numerosos parques urbanos fundados en el siglo XIX en ciudades de Europa y América. Espacios como el Central Park en Nueva York, y el Sefton Park y el Stanley Park en Liverpool, fueron diseñados a mediados del siglo XIX como lugares donde los citadinos pudieran convivir con la naturaleza, mejorar su salud y además relajarse en un paisaje rural (Taylor, 1999; Marne, 2001).

Esa visión de diseño constituyó parte del pensamiento de gente como Frederick Law Olmsted, diseñador del Central Park junto con Calvert Vaux entre 1858-1861. Olmstead y otros promotores destacaban como parte de las bondades de los parques su poder relajante, y la habilidad de los espacios verdes para disminuir la lucha antagónica de las clases sociales. Olmstead creía especialmente que los parques podían fomentar sentimientos de grupo sin importar la clase social, llevando salud para todos, en particular a los más pobres y desprotegidos y alejando a los hombres de vicios y otros comportamientos destructivos y no saludables (Taylor, 1999: 6). La visión de diseño de Frederick Law Olmsted incorporó también el concepto de mecanismo de control social mediante el diseño de un modelo de parque que funcionara como un agente efectivo de vigilancia (Taylor, 1999). Ese diseño permitiría a la clase media supervisar y controlar la conducta de la clase trabajadora durante su tiempo libre.

En Europa, la preocupación y el interés por la salud de los citadinos catalizaron el surgimiento del movimiento Garden City en la Inglaterra de fines del siglo XIX. Ese movimiento fue auspiciado por Ebenezer Howard, quien sugirió diseñar ciudades embellecidas con espacios verdes (las ciudades jardín). Howard proporcionó además uno de los primeros indicadores de planificación urbana al recomendar que las ciudades estuvieran rodeadas con cinturones verdes en una relación de cinco hectáreas de cinturón por una de tierra desarrollada (Miller, 1997).

Paralelamente, en Estados Unidos de América (EUA) surgió el movimiento City Beautiful, desarrollado, entre otros, por Frederick Law Olmsted Jr. y Daniel Burnham también a fines del siglo XIX. Los movimientos Garden City y City Beautiful fueron modelos de planificación urbana tendentes a crear parques públicos y mejorar la salud de los citadinos, por lo cual comprendían un 
diseño arquitectónico urbano con fundamentos sociales ("The Garden City Movement”, 1906; Salvador, 2003).

En los primeros años del siglo xx, el enfoque de control social de espacios como el Central Park se vio fortalecido con diversos movimientos reformistas en recreación urbana auspiciados por mujeres de clase media que promovían un entretenimiento familiar e infantil (Taylor, 1999). Después, esos movimientos resultaron en lo que Galen Cranz y Michael Boland (2004) denominan etapa de Parques de la Reforma, que se extendió desde 1900 hasta 1930 y que asimiló la recreación infantil como uno de sus principales objetivos. Cranz y Boland (2004) identifican, al menos en EUA, tres etapas históricas más en el desarrollo de los parques urbanos de 1930 a la fecha (cuadro 1); esas etapas consideran extender los beneficios derivados de los parques a diferentes grupos sociales. La visión de recreación y convivencia fue en un principio familiar, y en las dos últimas etapas se extiende para incluir a los residentes citadinos de manera general. La clasificación histórica de tipos de parque de Cranz y Boland es útil debido a que permite relacionar la meta social con el orden geométrico y los beneficiarios. De especial interés es la etapa actual, que desemboca en el tipo denominado parque sustentable, que tiene como meta la salud humana y la salud ecológica y, por lo mismo, provee al concepto de parque urbano una importancia ambiental y de conservación.

Sin dejar de reconocer la importancia ecológica que cumplen actualmente los espacios verdes, es de interés para este análisis centrarse por el momento en la función de inclusión social. Si se hace una revisión general de las etapas históricas a través de las cuales se han desarrollado los parques urbanos, se observa que la inclusión social ha sido uno de los objetivos principales en cada etapa. En cuanto al orden geométrico, en cada etapa éste se tiene que adaptar a las metas sociales, las cuales a su vez se traducen en beneficios dirigidos a los grupos privilegiados en cada tipo de parque. Parte de los beneficios se obtienen por medio de actividades recreativas que llevan a los grupos a hacer uso del espacio.

Una revisión histórica más puntual permite establecer que los primeros movimientos reformistas de parques tendieron a promover principalmente una moral y salud urbanas mediante el contacto de las familias con la naturaleza. Ese contacto se impulsó con paseos familiares, también se promovió la recreación familiar e infantil para evitar así la descomposición social en las ciudades y las actividades ilícitas como la delincuencia. Esa meta social se generalizó a los diferentes grupos sociales (Taylor, 1999; 


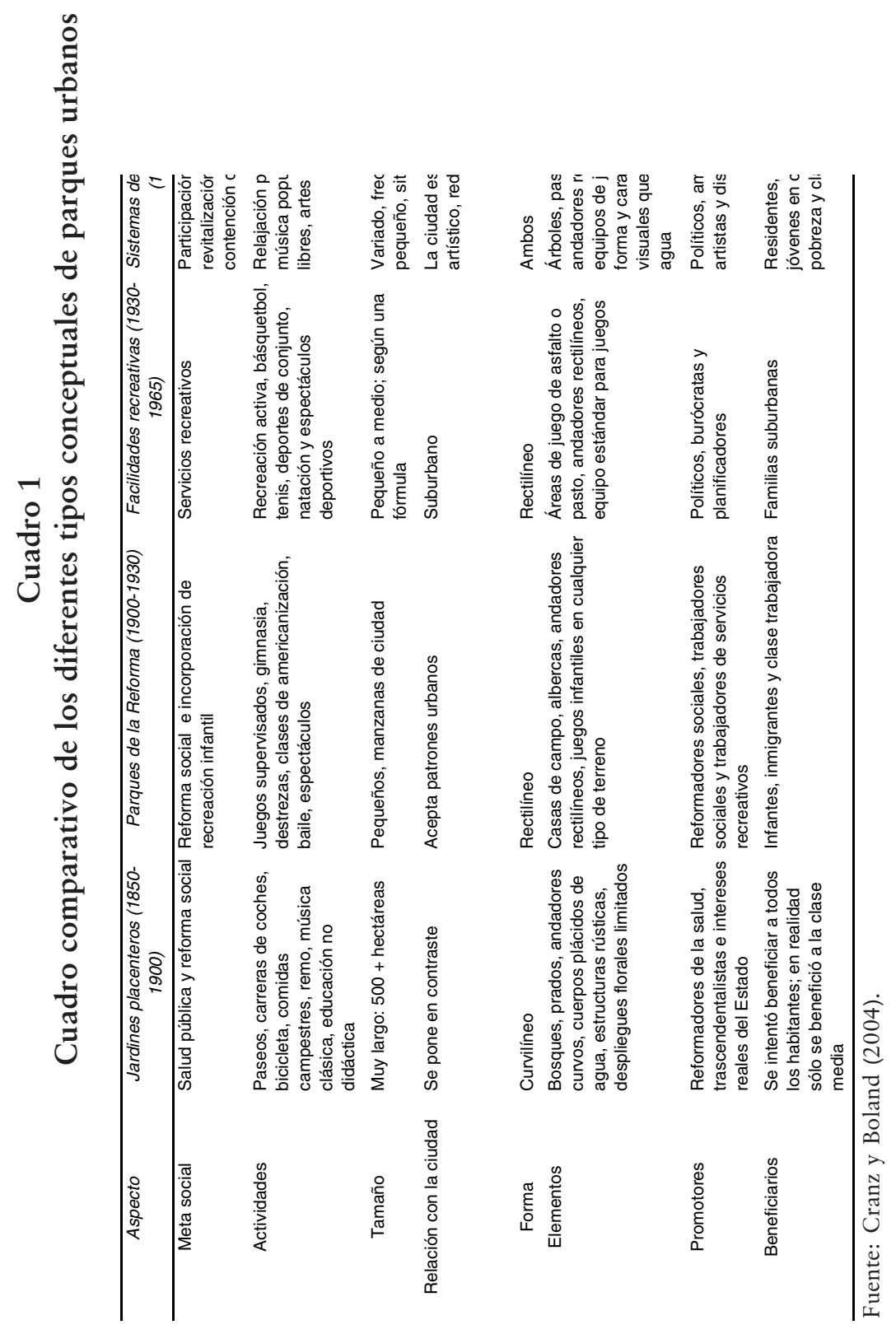


Marne, 2001). El establecimiento de ese objetivo, si bien su finalidad era lograr la inclusión social de todos los citadinos, resultó en una problemática de exclusión social, ya que los beneficiarios realmente fueron las familias de clase media que demandaban ese tipo de recreación en particular.

Como resultado de lo anterior, desde un inicio surgieron conflictos entre familias de clase trabajadora a quienes les interesaba más una recreación activa en los espacios, como actividades deportivas y reuniones, frente a aquellas familias de clase media que preferían un uso pasivo de disfrute del espacio verde (Taylor, 1999). Esta consecuencia tiene su origen en que se desconoció en principio la diversidad de gustos y preferencias que podrían tener los diferentes tipos de familias urbanas o suburbanas. Igualmente, si se habla de citadinos como grupo general, se tiene el riesgo de pasar por alto los diferentes modos de vida (diversidad cultural), que son decisivos en las preferencias recreativas. Los mismos riesgos se pueden extender si se pasa por alto que existen gustos, preferencias y demanda de facilidades ${ }^{4}$ recreativas diferentes a los concebidos a priori entre jóvenes y adultos, mujeres y hombres, casados y solteros, pobres y ricos, personas discapacitadas o no discapacitadas, etc. Consecuentemente, pasar por alto la diversidad recreativa origina no un espacio incluyente, sino uno excluyente y por lo tanto discriminatorio hacia ciertos grupos sociales.

De esta forma, y para cada una de las metas sociales de las diferentes etapas históricas, se pueden ir analizando los riesgos de exclusión social y discriminación caso por caso. Si bien históricamente los objetivos sociales de inclusión se han dirigido a integrar diferentes grupos a los espacios verdes, se tiene un riesgo latente de que la predilección por un grupo beneficiario, y también por actividades y reglas de uso, lleve a la exclusión u olvido tal vez inconsciente de otros. Ese favoritismo dentro de los espacios forma parte de los mecanismos de control social que pueden existir dentro de los espacios verdes.

Esa función de los espacios públicos como mecanismos de control social fue analizada por el filósofo Michel Foucault (1984) Salcedo (2002), describió cómo los mecanismos de control social se ejercen dentro de los espacios públicos excluyendo com-

\footnotetext{
${ }^{4}$ En este documento el término "facilidades recreativas" se emplea de manera general para referirse a infraestructura como las vías de acceso y andadores dentro del parque además de juegos infantiles, canchas deportivas y sanitarios junto con todo el mobiliario del parque como postes de luz, cajones de estacionamiento, bancas, fuentes y botes de basura. Incluyendo también servicios como agua potable y casetas telefónicas.
} 
portamientos no deseados por la sociedad. Esos mecanismos se ejercen por medio de una gama de posibilidades de uso espacial cuyos dos extremos corresponden, por una parte, a casos de desorden y, por otra, a casos de represión y marginación social (Yiftachel, 1998).

Hay que reconocer que los espacios públicos, incluidos los espacios verdes, son sitios donde los diferentes grupos sociales se ven sujetos a mecanismos de control que reprimen o permiten ciertos comportamientos. Esos mecanismos se dan en forma de reglas sociales que influyen en el diseño de los mismos espacios. Por lo mismo, el diseño arquitectónico de los parques urbanos es un mecanismo que favorece o restringe diversos usos en los espacios verdes (Marne, 2001; Rishbeth, 2001).

\section{Discriminación en parques públicos}

La interacción entre reglas de uso social y diseño arquitectónico de parques resulta en una variedad de problemas de desconsideración y discriminación que se manifiesta de diversas formas. Así, los parques públicos son sitios donde se puede ejercer la discriminación por género, ${ }^{5}$ raza, etnia y orientación sexual, entre otros. Esto se puede observar en el mismo diseño de algunos parques que no cubren las expectativas recreativas de los diferentes usuarios y además favorecen la aparición de múltiples conductas no deseadas en los espacios verdes, por ejemplo:

- Conductas delictivas como robos, drogadicción y alcoholismo.

- Surgimiento y/o fortalecimiento de una percepción de inseguridad y temores para hacer uso de los espacios verdes, aspectos encontrados en estudios de recreación en mujeres y otros grupos sociales.

- Persecución y agresiones a personas cuya presencia y/o actividades recreativas pudieran no ser bien vistas en los espacios verdes.

- Desconsideración hacia personas discapacitadas o que requieren cubrir una necesidad especial.

Esta situación resulta, a fin de cuentas, en espacios verdes subutilizados y en ocasiones vacíos, por lo cual las instalaciones re-

\footnotetext{
${ }^{5}$ Como discriminación por género se entiende lo expuesto por Lamas (1998: 6): el sexismo, o sea, la discriminación en función del sexo mediante el género.
} 
creativas y la vegetación con que cuentan corren el riesgo de deteriorarse e incluso dejar de existir si no se justifica su demanda social.

En los siguientes apartados se analiza y discute la forma en que surgen algunas conductas no deseadas en los espacios verdes, incluyendo sus efectos en los usos recreativos de mujeres, etnias, razas, homosexuales y personas discapacitadas.

\subsection{Percepción de inseguridad y delincuencia}

Sobre la percepción de la inseguridad y la delincuencia dentro de los espacios verdes, se puede establecer que son dos fenómenos relacionados. La primera se fortalece por la segunda, especialmente en aquellos grupos sociales que son sujetos de discriminación dentro de las ciudades o que derivan mayor percepción de inseguridad en los parques públicos por el diseño arquitectónico de éstos.

La percepción de inseguridad en parques públicos es una problemática que se ha encontrado especialmente en mujeres. Sin embargo, esa percepción también se ha reportado en minorías étnicas y raciales de algunas ciudades en EuA que temen al racismo en espacios urbanos, y en grupos sociales como hombres homosexuales, por temor a la homofobia. Aunque esta idea de inseguridad en mujeres, homosexuales y grupos raciales/étnicos se discute más adelante, es importante destacar ahora la relación que hay entre el diseño del espacio verde, la percepción de inseguridad y las actividades ilícitas que pueden ocurrir en los parques.

Respecto a las actividades ilícitas en parques públicos, la densidad y el tipo de vegetación, combinados con la hora del día y la mala iluminación nocturna, son un factor clave en la aparición de conductas delictivas como violaciones, robos, drogadicción y alcoholismo (Dascal, 1994). De esta forma, el diseño paisajístico y recreativo pensado para favorecer la convivencia social se convierte en magneto y refugio para delincuentes. Ellos pueden aprovechar la densidad y altura de la vegetación como escondite para sus actividades ilícitas, llegando incluso a valerse para el mismo fin de la infraestructura recreativa, como kioscos y canchas deportivas. La presencia de conductas delictivas en los espacios genera un clima de desconfianza entre los usuarios habituales de los parques. Como resultado de ello, los visitantes pueden responder de diferentes formas; por ejemplo: 
- Evitar hacer uso, a diferentes horas del día, de zonas que identifiquen como riesgosas; por ejemplo, lugares aislados y áreas de vegetación densa.

- Realizar sus actividades recreativas en compañía.

- Dejar de visitar el parque.

Consecuentemente, es necesario que los problemas de percepción de inseguridad de cada grupo social en los parques y sus localidades, junto con los fenómenos de asaltos y drogadicción, a veces presentes, se estudien con mayor detalle para determinar qué características del diseño arquitectónico y de la vegetación favorecen su aparición en los parques urbanos, y así adecuar estos últimos en beneficio de los usuarios (Aminzadeh y Afshar, 2004; De Vos, 2005).

\subsection{La mujer en los parques públicos}

Diversos parques actuales fundados a partir de mediados del siglo XIX fueron concebidos como paisajes rurales destinados a proporcionar espacios para la relajación y recreación de trabajadores y sus familias (Taylor, 1999). Ese tipo de parque, denominado jardín placentero (cuadro 1) por Cranz y Boland (2004), constituyó el primer movimiento de creación de áreas verdes urbanas en EUA. Al respecto, Cranz (1982, citado en Whitzman, 2002: 300) menciona que ese movimiento se extendió a través de Gran Bretaña, EUA, Australia y Canadá durante la primera mitad del siglo XIX con base en el impulso de valores morales en la población, fomentando la apreciación de lo bello y puro de la naturaleza y proveyendo espacios de recreación familiar alternativos en lugar de tabernas, centros de vicio y otros lugares idóneos para realizar conductas inmorales.

Esa antigua concepción de diseño urbanístico lleva a idealizar el espacio verde sólo como un sitio de recreación familiar, conduciendo a generalizaciones erróneas sobre hábitos recreativos. Sin embargo, de esa forma se empezaron a asignar las facilidades recreativas de acuerdo con lo que culturalmente los responsables de diseños de parques reconocieron como actividades recreativas para hombres, mujeres, niños, adolescentes y ancianos, o lo que es lo mismo, para papá, mamá, hijos de diferentes edades y abuelitos. Sin embargo, esa visión de diseño ha sido puesta en tela de juicio ya que no considera las expectativas recreativas de personas con un perfil diferente o les asigna erróneamente un papel predeterminado en el uso de los espacios recreativos, como en el caso de la 
mujer. Durante el siglo xx, el derecho de la mujer a usar parques públicos fue ampliamente discutido, debido a concepciones que todavía hoy promueven sólo actividades de recreación maternal. Además de aquellas otras que fomentan prejuicios, que llegan incluso a establecer que las mujeres decentes deben evitar áreas ajenas a los sitios de recreación infantil, especialmente al oscurecer para proteger su reputación y mantenerse a salvo de agresiones (Whitzman, 2002).

Por lo anterior, cabe preguntarse: si se concibe recreativamente a la mujer sólo como madre de familia, ¿dónde quedan las mujeres con otro perfil social?, como solteras, estudiantes, profesionistas, obreras, etc. Las mujeres, al menos por normas culturales, pueden ver restringido su uso recreativo en parques quedando excluidas en menor o mayor grado de los múltiples beneficios que aportan las áreas verdes, como el esparcimiento y mejoras en la salud por actividades deportivas. Esa concepción de recreación en mujeres sólo como madres de familia, ha llevado incluso a generar toda una serie de ideas y problemas sobre su tiempo libre en los espacios públicos. Por ejemplo, se ha llegado al extremo de decir que la mujer no tiene derecho de tiempo libre en espacios públicos, y a soportar más restricciones, como falta de tiempo, falta de programas recreativos, responsabilidades duales dentro y fuera del hogar y preocupaciones sobre la seguridad personal en los espacios, entre otras (Krenichyn, 2004).

Considerando lo anterior, se pueden identificar al menos dos factores en el espacio verde que pudieran excluir a la mujer: uno relacionado con la seguridad personal que ella pudiera derivar del diseño arquitectónico, y otro más resultado de la ausencia de facilidades y programas recreativos incluyentes, que permitan a mujeres con intereses diversos su incorporación a los múltiples beneficios recreativos y de esparcimiento que brindan los parques.

Sin embargo, no se pueden generalizar los factores de riesgo de exclusión de mujeres en los espacios verdes de diferentes ciudades del mundo. Kira Krenichyn (2004) menciona la importancia de investigar esos factores, aunque destaca que al menos en ciudades escandinavas, la mujer hace uso de los espacios públicos con audacia y sin temor. Igualmente menciona que en EUA algunos parques y plazas urbanas con mayor diversidad de usuarios también presentan tasas elevadas de mujeres que las utilizan. Por el contrario, otras investigaciones demuestran que la mujer está subrepresentada por percepción de inseguridad, por lo que prefiere usar los espacios verdes en un contexto familiar y de recreación y cuidado de infantes. 
Si se consideran las metas sociales de los tipos de parque descritos por Cranz y Boland (2004), se detecta una predilección por la recreación dentro de un contexto familiar, especialmente en aquellos tipos de espacio desarrollados entre 1850 y 1965. No es sino hasta el diseño de parque del tipo Sistema de Espacio Abierto cuando, según Cranz y Boland (2004), los beneficios se extienden para comprender a los residentes citadinos sin distinción. Ello representa un logro en la inclusión social de los espacios. No obstante, aun cuando el objetivo sea una inclusión equitativa de todos los residentes, hay que considerar el papel arquitectónico de la vegetación.

Las masas arboladas, si bien cumplen un papel de diseño estético y ecológico como en el tipo actual de diseño de Parque Sustentable, es importante considerar que su distribución y densidad pudieran constituir un mecanismo recreativo limitante, ya que diversos estudios han demostrado que pueden generar diferentes gradientes de percepción de inseguridad en los distintos tipos de usuario, como las mujeres. Según Carolyn Whitzman (2002), esa percepción se presenta cuando realizan solas actividades recreativas en los espacios verdes; por ejemplo, en masas densas de árboles y con condiciones de mala iluminación que pudieran favorecer asaltos y agresiones físicas y sexuales. Por lo anterior, es importante evaluar qué tanto influye el diseño paisajístico del parque en la percepción de inseguridad sobre el espacio. Hay que someter a discusión el hecho de que, si una estética de paisaje rural, ecológicamente sustentable, a veces denso e íntimo y constituido por árboles y arbustos que cortan la vista, si bien pudiera ser un mecanismo educativo y de relajación psicológica para algunos usuarios, pudiera, por otro lado, generar percepción de inseguridad en mujeres o en otros grupos sociales.

Respecto a la falta de facilidades y programas recreativos dirigidos a los usuarios, la visión sustentable actual de tipo de parque es una llamada de atención para considerar la recreación femenina más allá de los usos tradicionales que comúnmente se les han conferido a las mujeres. Es necesario dejar las concepciones a priori sobre lo que puede o no hacer una mujer en el espacio verde, hay que dejar que sea ella misma quien decida con base en sus gustos y preferencias. Por lo que es tarea del diseñador y administrador del espacio desarrollar las facilidades recreativas sin considerar que el género del usuario define la actividad que se prefiere realizar. Por ejemplo, las áreas de ejercicios físicos y los gimnasios al aire libre deberían ser concebidos teniendo en mente que serán usados tanto por hombres como por 
mujeres que seguramente tendrán diferentes capacidades y necesidades especiales.

Como se puede advertir, la percepción de inseguridad que se genera en las mujeres en los espacios verdes y la ausencia de facilidades y programas recreativos dirigidos a ellas, pueden constituir factores que disminuyan su satisfacción. Ante estos resultados, es necesario considerar e investigar la demanda social recreativa de la mujer y la percepción que deriva del espacio, incluyendo el marco histórico y cultural que ésta ha desempeñado en los espacios públicos de cada ciudad.

De acuerdo con los argumentos anteriormente expuestos, es necesario invitar a reflexionar a los responsables del diseño y la planificación de parques sobre qué expectativas de recreación cubren los espacios verdes en sus localidades. Esta reflexión debería extenderse por medio de una revisión histórica, para dejar que el espacio verde revele su origen y la finalidad con que fue creado. Es necesario considerar que desde una óptica de equidad e inclusión social, una definición rígida de recreación sólo como actividad familiar, educativa, ecológica y naturalista constituye sólo una parte de la demanda recreativa en los espacios verdes actuales. Igualmente, habría que meditar un poco sobre el efecto que tienen las concepciones a priori sobre los usos recreativos del parque, las cuales, aun cuando se hagan de la mejor manera, pudieran no estar respondiendo a las necesidades sociales, recreativas y de esparcimiento de los usuarios. Hay que dejar a un lado la rigidez de los conceptos y ser más flexibles en el diseño del espacio verde y en lo que se entiende por recreación.

\subsection{Presencia del grupo homosexual en los espacios verdes}

En la esfera pública no es extraño observar la presencia de parejas y grupos homogéneos de hombres o mujeres, o parejas y grupos mixtos que conviven socialmente para divertirse con diferentes objetivos: jugar, buscar nuevas amistades o incluso flirtear hombres con mujeres o mujeres y viceversa. Por ello, es común ver en los espacios públicos parejas heterosexuales que manifiestan sus emociones con muestras de afecto y que se apropian del espacio según las reglas sociales que favorecen actividades, gustos y orientaciones sexuales que culturalmente se ven como propias de un hombre y de una mujer. Sin embargo, en los espacios públicos esas reglas sociales se ven rebasadas y transgredidas por grupos de personas con una orientación sexual diferen- 
te, como homosexuales, lesbianas ${ }^{6}$ y hombres y mujeres transgénero. ${ }^{7}$ Por lo cual, espacios urbanos como los parques públicos pudieran no ser del todo favorecedores para las actividades de dichos grupos.

De acuerdo con los estudios de caso e investigaciones revisadas de geografía urbana y recreación, la marginación, discriminación y persecución en parques públicos está más documenta$\mathrm{da}$ en el caso de homosexuales, posiblemente por las mismas actividades recreativas y de ligue o búsqueda de parejas sexuales (cruising) que ellos llegan a realizar en estos lugares. Esto puede percibirse también por las agresiones a homosexuales, reportadas por Amnistía Internacional (2001), en espacios públicos y parques urbanos, y que están relacionadas con una aguda homofobia presente aún en diversas ciudades del mundo.

Diversos estudios retrospectivos y actuales (Chauncey, 1994; Sánchez y López, 2000; List, 2001; Sánchez, 2002; De Vos, 2005) sobre comportamiento homosexual urbano señalan que los parques urbanos constituyen, para los homosexuales, sitios de socialización y de actividades recreativas que pueden llegar a favorecer su identidad como personas y como miembros de una comunidad con cultura propia en los espacios urbanos. La presencia de los homosexuales en los espacios verdes ha sido documentada históricamente por George Chauncey (1994), quien en un análisis de la cultura urbana y de la vida social de los homosexuales de principios del siglo xx en Nueva York, señala que los espacios verdes fueron sitios populares de reunión ante una sociedad discriminadora e incomprensiva para ellos.

En su estudio, Chauncey (1994) expone cómo el concepto de paisaje rural y disfrute de la naturaleza en parques, favorece diferentes actividades de los homosexuales, como la socialización y búsqueda de parejas sexuales. Ello constituye un aspecto interesante de las actividades homosexuales en los parques urbanos, ya que aunque se llevan a cabo en espacios públicos, consideran el uso de códigos y subterfugios. Esos códigos, junto con el mismo diseño arquitectónico y la vegetación del espacio, interactúan para excluir intrusiones y comportamientos hostiles de personas ajenas a este grupo (De Vos, 2005).

\footnotetext{
${ }^{6}$ Para esta investigación, el término lesbiana comprende a todas las mujeres que gustan de tener contactos eróticos con otras mujeres, sin considerar ninguna excepción.

${ }^{7} \mathrm{El}$ término persona transgénero se refiere en este estudio a todos aquellos hombres o mujeres que, independientemente de su orientación sexual (heterosexual, homosexual o bisexual), adopten pautas, comportamientos y rasgos físicos del género opuesto.
} 
De acuerdo con Arturo Sánchez (2002), los parques son espacios que favorecen las interacciones homoeróticas; sin embargo, han sido estigmatizados como escenarios de intimidad criminal de la cultura homosexual (Berlant y Warner, 2005). Debido a dicho estigma, la popularidad que adquirieron los parques urbanos en diferentes ciudades condujo a la pronta persecución y represión de homosexuales en tales sitios. Chauncey (1994: 183), documenta las primeras redadas policiacas de homosexuales en sitios como el Central Park en la segunda década del siglo xx:

La enorme presencia de homosexuales en los parques motivó una pronta respuesta de los policías. Éstos generalmente acudían vestidos de civil a las áreas de ligue y flirteo, con el objetivo de atrapar homosexuales; p. ej. durante la primera mitad de 1921, se realizaron treinta y un arrestos alrededor del Zoológico de Central Park. La policía realizaba periódicamente redadas y arrestos en masa de homosexuales sospechosos en los parques. Igualmente inflaban sus estadísticas de arresto, para obtener más publicidad y forzar a los homosexuales a cambiar su forma de ligue.

Pese a tal discriminación y persecución, los parques urbanos actuales siguen siendo espacios de interacción homosexual, lugares que en buena parte han sido conquistados con apoyo de movimientos activistas en favor de los derechos homosexuales y lésbicos en la esfera pública.

Actualmente, los grupos activistas se apoyan en políticas internacionales que pugnan por el respeto a los derechos humanos, y uno de sus objetivos es promover la tolerancia hacia homosexuales, lesbianas y personas transgénero en los espacios públicos, lo que ha permitido que se reconozca el uso que tales sectores sociales hacen de los parques públicos. Algunos de los logros de esos grupos son:

- La introducción del tema de la apropiación y uso recreativo en espacios urbanos como parques en las políticas públicas de gobierno, tal como lo documenta Fran Martin (2000) en Taiwán.

- $\quad$ El origen de parques públicos más tolerantes, como Riis Park ${ }^{8}$ en Nueva York, el cual cuenta con áreas donde

\footnotetext{
${ }^{8}$ Aunque propiamente Riis Park no es un espacio verde, se incluye como ejemplo debido a que se considera parque público; de hecho, hasta 1974 su administración fue responsabilidad del New York City Parks and Recreation Department y después del National Park Service, que lo incorporó al del sistema Gateway National Recreation Area (Low et al., 2005)
} 
conviven homosexuales y lesbianas compartiendo el espacio con otros visitantes (Low et al., 2005).

- La consideración de usos y actividades recreativas de homosexuales en propuestas de manejo y usos recreativos en áreas verdes, como lo documenta De Vos (2005) respecto de la ciudad de Gante, en Bélgica.

Sin embargo, en otras urbes como la Ciudad de México, los parques públicos siguen siendo sitios de discriminación homosexual, acoso y agresiones policiacas (Sánchez y López, 2000). Esa discriminación explica algunos resultados de investigaciones sobre homosexuales en espacios verdes, como:

- Las agresiones físicas o verbales por parte de otros usuarios de los espacios o incluso de la misma autoridad responsable de brindar seguridad y orden social.

- Aparición o incremento en la percepción de inseguridad y temores a sufrir agresiones al hacer uso del parque.

- La exclusión de homosexuales en los espacios.

Por lo anterior, no es extraño que Amnistía Internacional (2001) informe que en países como India, los parques urbanos son sitios de agresiones policiales a homosexuales, quienes desgraciadamente sólo en esos sitios pueden socializar entre ellos.

Las evidencias actuales de persecución y discriminación permiten afirmar que no existe un reconocimiento público generalizado por parte de quienes administran de los espacios verdes y de otros usuarios de que los homosexuales tienen derecho a ejercer sus actividades recreativas dentro del parque público. Un primer deber de las autoridades citadinas es reconocer ese derecho, si es que se quiere avanzar en la inclusión social dentro de los espacios públicos. Mientras desconozca o pase por alto la existencia de la actividad recreativa homosexual dentro de los espacios verdes, existe el riesgo de agresiones por parte de cuerpos policiales y de otros grupos sociales.

Se requieren acciones afirmativas -como reglas de uso del espacio equitativas y campañas de difusión- por parte de las autoridades y de los mismos grupos sociales que permitan generar un clima de tolerancia y respeto hacia personas con preferencias sexuales diferentes. Para ello, es necesario considerar que el acercamiento entre administradores y autoridades del parque y los diferentes grupos sociales es fundamental para generar un clima de respeto y cordialidad en el uso de los espacios verdes. Esta aproxi- 
mación es necesaria ya que las características de paisaje e intimidad en el espacio verde, importantes para el ligue homosexual, son a su vez elementos amigables para actividades recreativas como la relajación y la observación del paisaje y de la vida silvestre. Por lo anterior, aquí se tienen dos grupos sociales con intereses diferentes que comparten las mismas áreas recreativas. También es necesario reflexionar sobre cómo un espacio que fue creado con fines de recreación pasiva es usado con intereses distintos, lo que refleja, a fin de cuentas, que el espacio es dinámico y no neutro y adaptable a necesidades de diversos usuarios.

Sin embargo, esa cualidad del espacio se puede traducir en diversas desventajas y generar conflictos que lleven a la exclusión. En aquellas ciudades donde la homosexualidad no es bien vista en los espacios públicos, pudiera estar creando rechazo y agresiones por parte de usuarios que comparten el espacio íntimo y relajante, o por aquellos que quisieran derivar satisfacción y seguridad a partir de espacios abiertos, iluminados y con mayor vigilancia. En ambos casos, los grupos sociales podrían sentirse con mayor derecho para reclamar su uso del espacio y excluir a personas con comportamientos no bien vistos por la sociedad (Whitzman, 2002).

Por lo anterior, y considerando una perspectiva de equidad, nuevamente destacamos la importancia de flexibilizar el concepto de recreación considerando además las reglas de uso social en los parques. Ésta sería una condición necesaria, pero no suficiente, para generar un clima de respeto y tolerancia dentro de las áreas verdes. La cualidad de adaptación del espacio descrita anteriormente refuerza que es necesaria la disposición de los diversos grupos sociales para consensuar, junto con los administradores, las características de diseño que favorezcan sus actividades y las mejores formas para asignar y/o establecer espacios de uso de acuerdo con sus necesidades.

Obviamente, mientras que la homosexualidad siga siendo considerada como una actividad intolerable, e incluso a veces ilícita, en las sociedades urbanas, es difícil que se lleve a cabo una conquista del espacio por parte de la comunidad homosexual.

Por otra parte, es necesario ampliar a detalle los estudios de demanda social recreativa de ese grupo social. Además, existen aspectos como la interacción entre el diseño de los espacios y los códigos de conducta homosexual, que distan aún de conocerse del todo y que ameritan, por sí solos, ser considerados en investigaciones futuras. 
También es importante cubrir el vacío en el conocimiento de los usos recreativos que las lesbianas hacen en los parques, ya que generalmente han sido consideradas invisibles en los espacios públicos, como lo sugiere Julie Podmore (2001). Aunque existen estudios en los que se hace referencia a la actividad lésbica en los parques urbanos (Chauncey, 1994; Low et al., 2005), éstos no pasan de ser sólo informes de la presencia de ese grupo, o bien, se les considera compartiendo espacios recreativos con homosexuales. Sin embargo, tales estudios no exploran los usos ni las actividades recreativas que llevan a cabo las lesbianas en estos lugares.

La misma aridez en los estudios de recreación urbana y parques públicos se encuentra en relación con las personas transgénero, dejándose de lado la posibilidad de una falta de interés en investigaciones sobre geografía urbana y recreación de lesbianas y personas transgénero en espacios verdes. Esta aridez en el tema pudiera también verse afectada porque:

- Las técnicas y métodos empleados en geografía urbana y recreación en espacios verdes no han sido las adecuadas para conocer los actividades recreativas de lesbianas y personas transgénero y, por lo mismo, pasan desapercibidas.

- Posiblemente estén en mayor o menor grado ausentes en los parques por la discriminación presente en los espacios públicos. Especialmente en el caso de aquellas personas cuya condición transgénero es notoria, al mezclar características físicas femeninas y masculinas, lo cual los podría hacer más vulnerables a ser discriminados y agredidos.

\subsection{Aspectos étnicos y sociales en los parques públicos}

En este análisis se han descrito diversas situaciones de marginación y discriminación en los espacios verdes, a veces sutiles, como en el caso de la mujer, y en otras agresivas, como en el caso de los homosexuales. Sin embargo, seguramente ninguna de esas dos situaciones, al menos durante todo el siglo xx, ha adquirido tal notoriedad como la discriminación por motivos raciales/étnicos.

Recientes investigaciones en parques urbanos relativas al aspecto racial/étnico, demuestran que:

- El temor a ser discriminado por cuestiones raciales/étnicas persiste aún, especialmente en ciudades que albergan 
diversas minorías étnicas/raciales (Burgess et al., 1988; Rishbeth, 2001).

- Las percepciones sobre el espacio y los gustos y preferencias recreativos pueden ser diferentes de acuerdo con el origen étnico/racial (Payne et al., 2002; Sasidharan et al., 2005), y por lo general no son considerados en los planes de diseño del parque, especialmente en referencia a aquellos grupos minoritarios cuya demanda social no alcanza a ser cubierta.

Ambos resultados afectan el uso recreativo y, por lo tanto, la satisfacción que los grupos étnicos/raciales pudieran derivar de los espacios.

En el mejor de los escenarios posibles, los grupos adecuan sus actividades al espacio, y ante una percepción de inseguridad y/o discriminación, pueden optar por realizar sus actividades recreativas en espacios abiertos, bien iluminados y acompañados. En otros escenarios no tan optimistas, las personas amoldan los espacios a sus necesidades, pudiendo llegar a tener conflictos con los administradores del parque. Éste es el caso de aquellos espacios verdes que carecen de áreas acondicionadas para eventos y fiestas familiares, por lo que los usuarios se ven en la necesidad de adaptar algunas zonas del mismo. De esta forma, las reglas de manejo del parque pueden verse quebrantadas, generando un efecto negativo en áreas que en algunos casos pudieran estar destinadas a otros tipos de recreación o bien estar sujetas a conservación.

Por lo anterior, es necesario encontrar técnicas y métodos que permitan identificar la percepción del espacio y la demanda social recreativa de los grupos étnicos/raciales, y desde una perspectiva de equidad, hacerlo extensivo a los diferentes grupos sociales que visitan los parques urbanos.

En este trabajo, se han empleado, a la par, los términos raza y etnia sin que ello implique el mismo significado. Es necesario considerar esta diferencia conceptual, especialmente por el enfoque desde el cual se sugiere desarrollar los estudios de etnología, etnografía y recreación urbana, que se comentarán más adelante. Se entiende como raza el conjunto de todas aquellas personas que tienen características físicas en común, y como etnia, una población cuyos integrantes comparten memoria histórica, uno o más elementos de cultura, vínculos con una patria y con creencias de un ancestro común (Hutchinson y Smith, 1996: 6, citados, en Rishbeth, 2001: 352). 
Los estudios etnográficos y etnológicos constituyen el medio para atacar el problema de inclusión social considerando la demanda recreativa de los diferentes grupos sociales con base en sus valores culturales. Este enfoque de trabajo en espacios urbanos ha llevado a Setha Low y colaboradores (2005: 205) a definir el término cultura como un paquete abstracto de valores, prácticas y modos de vida que se emplean para sobrevivir en un ambiente particular.

Desde ese punto de vista, este enfoque puede considerar que los diferentes modos de vida determinarán el uso recreativo y la percepción que los diversos grupos sociales asignan a los espacios verdes urbanos. Si estos espacios se visualizan en un horizonte de tiempo, se transforman en agentes activos que cambiarán de acuerdo con los gustos y preferencias de los usuarios. De esta forma, el estudio de dichos modos de vida permitirá adecuar los diseños arquitectónicos de los parques y cubrir la demanda social en forma de paisajes incluyentes que consideren los gustos y preferencias recreativas que poseen los diferentes grupos sociales.

Si se ve al espacio como un agente activo y dinámico de inclusión social, entonces es necesario identificar qué grupos sociales visitan el parque (adolescentes, personas solteras, familias, etnías, razas, homosexuales, entre otros) e investigar la percepción que cada grupo tiene del espacio verde y los usos recreativos que se realizan en los mismos. Este enfoque de inclusión social en las investigaciones que se desarrollan en parques urbanos, permitirán obtener resultados como los encontrados por Paul Gobster (1998) y que sirven para mejorar el diseño de los espacios, por ejemplo:

- En principio, considerar el parque como un agente activo y dinámico de inclusión social permite concebir este espacio como un lugar que se puede ajustar a las necesidades del usuario y por lo tanto resultar en un magneto verde de grupos sociales, étnicos y raciales diferentes, siempre y cuando se cubra la demanda recreacional de dichos grupos. Por lo que la diversidad de los usuarios y la localización de los espacios entre localidades social o étnicamente diferentes no deberían ser impedimento para obtener tal magneto.

- El parque urbano se podría considerar como una pared verde sólo en casos donde se pase por alto la iden- 
tificación de grupos sociales y sus percepciones y usos dentro del mismo.

- $\quad$ Aunque se puedan presentar problemas de uso, como percepción de inseguridad y desplazamiento de usuarios por discriminación, éstos podrían ser atacados si se localizan los sitios recreativos compartidos por diversos grupos raciales, étnicos y sociales en un mismo parque y si se desarrollan estrategias y programas recreativos que permitan la interacción, tolerancia y respeto entre los diferentes tipos de visitantes.

Estos resultados, nuevamente, evidencian la importancia de considerar al espacio verde como un agente dinámico que se puede ajustar a los gustos y preferencias de los visitantes con el paso del tiempo. De ahí la importancia de conocer la demanda social recreativa de los diferentes grupos sociales. Este enfoque induce también a buscar los métodos y formas por los cuales se puede llegar a la obtención de usos recreativos consensuados que permitan la convivencia dentro de un marco de respeto y tolerancia entre usuarios diferentes, como mencionamos antes. De esos métodos y formas se hablará más adelante.

\subsection{Espacios verdes, discapacidades y necesidades especiales}

Los grupos hasta ahora mencionados carecen, en diferentes grados, de la oportunidad de interactuar en los espacios y obtener los beneficios que de ellos se derivan. No obstante, y considerando la definición de equidad de Scott-Webber y Marshall-Baker (1998), faltaría mencionar aún a aquellas personas que poseen alguna discapacidad física que les impide acceder sin restricciones a los espacios urbanos, o bien que requieren cubrir alguna necesidad especial con el mismo fin.

Aunque en algunos casos la exclusión pudiera estar relacionada con el diseño arquitectónico del espacio, es posible también que la aceptación social, la estigmatización y la discriminación influyan en la participación recreativa al aire libre de personas discapacitadas (Henderson y Bendini, 1995, citado en Williams et al., 2004). La influencia de ambas posibilidades ha sido demostrada para la población de personas con discapacidades motrices de Estados Unidos. Existen resultados que demuestran que es más probable que esa población se niegue a participar en actividades recreativas por preocupación sobre seguridad personal 
y facilidades recreativas inadecuadas, que una población no discapacitada (Williams et al., 2004).

Para poder hablar de restricciones en los espacios públicos, es conveniente establecer primero qué comprende una discapacidad. Respecto a este término, Deborah Park y colaboradores (1998: 9-10) consideran que una discapacidad física refiere no sólo a personas con inhabilidades motrices (como usuarios con silla de ruedas), sino también a personas con inhabilidades sensoriales (ciegos, débiles visuales, sordos, etcétera).

De acuerdo con estas posibles formas de discapacidad, los espacios públicos podrían presentar diversas restricciones que podrían ser comparables, en algunos casos, a diferentes tipos de barreras físicas presentes en los espacios públicos y que impiden el acceso y/o el desplazamiento. Sin mayor análisis, se podrían señalar al menos las siguientes dos restricciones para discapacitados: escalones y pendientes que entorpezcan o impidan el traslado en silla de ruedas, y falta de señalizaciones dirigidas a personas ciegas y débiles visuales.

Sin embargo, es importante señalar que la apreciación de Park y colaboradores (1998) se puede extender, tal como lo hacen Scott-Webber y Marshall-Baker (1998), si se considera la definición de equidad. Así, se incluye a personas que por envejecimiento vean deteriorada su capacidad para acceder a diferentes espacios, o bien a todo aquel sujeto que requiera cubrir una necesidad especial con el mismo fin. Un ejemplo de esas necesidades especiales en áreas urbanas serían las de aquellos usuarios de parques que empujan carreolas con bebés durante sus actividades recreativas. Esas personas, aunque no son discapacitadas, tienen que sortear diferentes barreras, como escalones y pendientes en los espacios, similares a las que confrontan las personas en silla de ruedas.

Las restricciones y barreras tienen que ser identificadas por los responsables del diseño de los espacios verdes, y son ellos quienes deben solucionarlas, ya sea modificando el espacio o proporcionando las facilidades necesarias. Algunas recomendaciones para ello podrían ser:

- Seleccionar el material y forma adecuada de los andadores para que no entorpezcan el desplazamiento de personas con problemas de movilidad o que requieran cubrir alguna necesidad especial. Por poner un ejemplo, los andadores con pendientes elevadas y escalones altos pueden constituir barreras infranqueables en algunos casos. 
- Elaborar rampas para el acceso y desplazamiento de personas con capacidades diferentes o con alguna necesidad especial que permitan el acceso a las áreas e instalaciones recreativas.

- Diseñar y colocar señalizaciones adecuadas que guíen a personas ciegas y débiles visuales dentro del parque.

- Elaborar programas y servicios recreativos incluyentes que permitan la incorporación de las personas por sus gustos y preferencias, sin excluir, a priori, a quienes padecen alguna discapacidad o necesidad especial. Dejar que hable el grupo en cuanto a sus gustos y preferencias de recreación.

El no tomar en cuenta a las personas discapacitadas en los espacios verdes se puede traducir en discriminación. Como se mencionó, un primer paso para corregir esa falla es reconocer el derecho de los diferentes grupos sociales a beneficiarse de las bondades recreativas de los espacios verdes. Ello implica la conscientización de los administradores y, en este caso, especialmente de los responsables de diseñar el espacio arquitectónico y las facilidades recreativas. Olvidar el acceso, desplazamiento y actividades recreativas de una persona discapacitada dentro de un espacio verde, es negar el derecho de uso recreativo. Consecuentemente, negar el derecho de uso recreativo es discriminar a una persona discapacitada, sin que por ello se hable de una agresión física o una persecución, como pudiera ser el caso de la discriminación étnica-racial o la discriminación a un homosexual dentro de un parque.

Por otra parte, al igual que en el resto de los grupos, es indispensable conocer la demanda social recreativa de personas discapacitadas en los espacios verdes, para determinar sus preferencias dentro de toda la gama de actividades que se llevan a cabo y, de esa forma, conocer los requerimientos y adecuaciones que se deben realizar en las instalaciones para recibir a los diferentes usuarios.

\section{Estrategias para la inclusión de grupos marginados}

El análisis sobre discriminación y falta de consideración en los espacios de los cuatro grupos estudiados en este trabajo, manifiesta una urgente necesidad social de redefinir los diferentes espacios urbanos bajo una visión de equidad. Esa redefinición permitirá que espacios públicos como los parques favorezcan la inclusión 
a través del desarrollo de ambientes urbanos que absorban un amplio espectro de capacidades y discapacidades humanas.

Sin embargo, esa visión incluyente aplicada en la planificación y manejo de los parques tiende a complicarse debido a que los especialistas y responsables de los parques urbanos no están del todo capacitados para conciliar los intereses de los diferentes grupos sociales dentro de nuevas propuestas de manejo y administración. A lo anterior hay que agregar que diversos parques urbanos actuales fueron concebidos históricamente con un diseño paisajístico predominantemente rural y de acuerdo con un concepto de recreación familiar. Si bien ese enfoque ha evolucionado a un tipo conceptual de Parque Sustentable, el riesgo de exclusión social aún exite si el administrador y el diseñador del espacio no reconocen la diversidad de los residentes citadinos que pueden hacer uso del parque. Este esquema se vuelve a complicar una vez que se asume la existencia de esquemas de recreación pasiva y activa que se pueden contraponer fácilmente; por ejemplo, relajación y contemplación del paisaje frente a actividades deportivas como fútbol soccer, béisbol y básquetbol.

La asignación de usos recreativos dentro de los espacios verdes puede conducir a problemas en donde satisfacer los gustos, preferencias y necesidades de determinado grupo social podría afectar negativamente los de otros. Ante esta problemática, los espacios verdes no pueden restringirse únicamente a proporcionar ciertos usos recreativos familiares, o bien, ciertos diseños de paisaje ecológico o rural. Y tampoco es posible seguir diseñando los espacios pensando en usos recreativos a priori. Si lo que se quiere es operar con espacios verdes incluyentes, se requiere como primera condición flexibilizar la definición de recreación en los espacios públicos y determinar la demanda social recreativa de cada grupo.

La contraposición que pueda haber en la demanda social de los diferentes grupos conduce a una visión integral de todos los usuarios y a considerar la participación ciudadana, de cuya utilidad se hablará en el siguiente apartado. Por lo anterior, es necesario instrumentar acciones integrales, buscando puntos de equilibrio en la asignación de áreas de actividades para diferentes grupos. En donde se favorezcan las preferencias, de ser posible de todos, o en su defecto de la mayoría de ellos. Al considerar el tipo conceptual de Parque Sustentable, habrá también que prever que los objetivos de conservación de vida silvestre pudieran no ser compatibles con determinados tipos de recreación u otros usos. Es el caso de algunas actividades que pudieran interferir 
con el desarrollo de la vida silvestre, como escuchar música, practicar deportes que generen ruidos o que impacten directamente en la vegetación. Es necesario que los biólogos y especialistas en conservación evalúen y analicen estos efectos.

Els de Vos (2005) sugiere que, debido a la imposibilidad de que un solo parque cubra las expectativas de todos los grupos sociales en una ciudad, es necesario se generen nuevas políticas urbanas tendentes a desarrollar un sistema citadino diversificado de parques.

Dentro de ese sistema, cada espacio verde pudiera estar basado en diferentes conceptos de planificación, diseño arquitectónico, posibilidades de participación ciudadana, valores culturales y usos recreativos, ecológicos y educativos. Esa visión, que en este trabajo se denominará "paisajística”, permitiría considerar una diversidad de funciones de utilidad, como recreación, conservación, educación, etc. Una gama de posibilidades diseñada y distribuida espacialmente en el paisaje urbano, donde cada parque pudiera satisfacer las necesidades, gustos y preferencias de determinados grupos sociales. Consecuentemente, es necesaria una visión paisajística integral en el diseño, manejo y administración de los parques, no como entidades aisladas, sino como un Sistema Integral de Espacios Verdes Citadinos. En ese Sistema, cada área verde tendría una función principal de utilidad, determinada por su respectiva demanda social. Así, existirían diferentes tipos de parque que contendrían toda la gama de posibilidades de uso recreativo, ecológico, educativo, histórico y de conservación. Esa visión "paisajística", basada en principios de sustentabilidad, hace necesaria la concientización de los planificadores de parques en relación con la importancia de los valores culturales de los grupos sociales. Es esencial aceptar que esos valores se manifiestan en forma de prácticas y estilos de vida que determinan el uso que se le da a los espacios urbanos y también la demanda social de áreas verdes.

\subsection{Demanda social recreativa, participación ciudadana y planificación de los espacios verdes}

Se han aplicado diversas técnicas para conocer la demanda social recreativa en espacios urbanos. Entre éstas se tienen investigaciones históricas, entrevistas, evaluaciones participativas, encuestas, conteos y caracterizaciones de usuarios por medio de observaciones en sitio. Todas estas técnicas pueden ser incorporadas en diferentes modalidades de participación ciudadana en 
los espacios verdes. Diversos congresos y acuerdos internacionales, como la Carta de la Habana (2001), el Programa Hábitat y la Declaración de Estambul de la Organización de la Naciones Unidas (Centro de las Naciones Unidas para los Asentamientos Humanos, 2005), recomiendan considerar la participación ciudadana en los planes de asignación y diseño de los espacios verdes. Hay que mencionar que dentro del tema de desarrollo sustentable, la participación de los grupos sociales es fundamental, tal como refieren Raúl Pacheco y Obdulia Vega (2001: 26).

En el discurso sobre desarrollo sustentable, el concepto de participación ciudadana es elogiado como la piedra nodal sobre la que se puede fincar un modelo de desarrollo económicamente próspero, ecológicamente protector y socialmente sustentable. La participación de la sociedad en la construcción, diseño e implementación de políticas ambientales ya no es una opción sino un prerrequisito si se habla de un desarrollo sustentable.

Consecuentemente, la participación -en sus diferentes modalidades, como mesas redondas multiparticipativas y coaliciones ambientales de organizaciones no gubernamentales (Pacheco y Vega, 2001) - es un instrumento clave en la solución de conflictos públicos. Las modalidades de participación se caracterizan por trabajar de acuerdo con un esquema de diálogo y cooperación, lo que es una ventaja que les permitiría obtener programas de diseño, manejo y consensar usos recreativos en áreas verdes, asunto que, a su vez, repercutiría favorablemente en la calidad de las instalaciones recreativas y su vegetación (Dascal, 1993; Dascal, 1995; Jones, 2002a y 2002b; Speller y Ravenscroft, 2005).

Sin embargo, la generación de un proceso participativo en las diferentes fases de desarrollo de las áreas verdes requiere que se cumplan algunos aspectos, entre los cuales se pueden mencionar los siguientes:

- Disponibilidad de los diferentes grupos sociales para participar libremente en un conjunto social integral.

- Que no se excluya del proceso participativo a determinado grupo o persona.

- Información disponible para discutir y consensar aspectos ligados a las percepciones de los diferentes grupos sobre el espacio y sus particulares gustos y preferencias recreativas.

No hay que olvidar que se está hablando de una diversidad urbana que puede llegar a comprender diferentes grupos, cada 
uno con intereses y necesidades particulares, y que en algunos casos pudiera existir intolerancia social hacia alguno de ellos. La cohesión social entre grupos diferentes se puede lograr siempre y cuando se alcance un clima de respeto y tolerancia y se reconozca el derecho de uso a grupos que, en algunos casos, históricamente han sido sujetos de olvido, por ejemplo, etnias, mujeres, homosexuales y personas discapacitadas.

La cohesión social puede llegar a ser un aspecto delicado y difícil de lograr en algunas ciudades del mundo; como en el caso de México, donde 39.1\% de la población considera que la exclusión significa impedir la participación de alguien, y 25.3\% la asocia también con descartar a una persona de la sociedad. Desfavorablemente, México también es un país donde, en general, nueve de cada 10 mujeres, indígenas, discapacitados, adultos mayores, homosexuales y pertenecientes a minorías religiosas se sienten discriminados. De estos grupos, 94.7\% de homosexuales, $94.4 \%$ de discapacitados y $94.2 \%$ de mujeres perciben que en México hay discriminación hacia ellos por su condición (Secretaría de Desarrollo Social, 2005). Si bien esa discriminación se reporta como más importante dentro de los ambientes laborales y de derecho al trabajo, es necesario extender esta investigación para determinar el porcentaje de discriminación en espacios públicos, como las áreas recreativas.

En relación con la información disponible, que es necesaria dentro de un esquema de participación social de áreas verdes, se estaría hablando de inventarios de superficie verde, facilidades recreativas, estadísticas sobre usos y conocimiento de gustos, preferencias y necesidades de los usuarios dentro de los espacios. La inexistencia o restricción de esa información limitaría la toma de decisiones y acuerdos que se puedan hacer para adecuar diseños, asignación de usos y generación de programas de áreas verdes. Por ello, es necesario que los administradores de los parques incentiven la creación de bases de datos automatizadas y sistemas de información pública de los espacios verdes recreativos.

Como se comentó, los administradores pudieran no estar del todo preparados para considerar la diversidad de intereses recreativos. Sin embargo, esa misma deficiencia podría llevarlos también a pasar por alto las bondades de la participación social y a desconocer los resultados derivados de los procesos participativos que son de interés para la comunidad. Por lo mismo, la ausencia o desconocimiento de las bondades de la participación social arrastrarían consigo el incumplimiento de la demanda social en las áreas verdes, resultando ello, como mencionamos en 
otros apartados, en espacios subutilizados y vacíos. Esa situación a su vez influiría en la percepción de inseguridad, creándose de esta forma un círculo vicioso que resulta en un decaimiento de la calidad de las masas arboladas y de los servicios y recursos recreativos con que cuenta el espacio. Además, los conflictos sociales en los espacios pueden agudizarse por asaltos, agresiones y persecuciones en contra de grupos vulnerables. Tales problemas abren la posibilidad de que el deterioro en la calidad de los parques incida en una disminución de la superficie verde de la localidad. Y eso posiblemente aumentaría aún más la competencia con otros usos del suelo, como comerciales, residenciales y para estacionamientos, los cuales serían favorecidos debido a los beneficios económicos que derivan de ellos. En consecuencia, es muy importante estimar el valor económico de los servicios sociales, recreativos y ambientales que prestan los parques urbanos.

La ausencia de valor en términos monetarios o de precios de mercado de tales servicios, pone en franca desventaja el uso recreacional en los espacios verdes, debido a que la planificación urbana puede emplear herramientas económicas como el análisis de costo-beneficio en la toma de decisiones para asignar y dar prioridad a determinados usos del suelo. Sin embargo, el hecho de que se carezca de tales valores económicos no quiere decir que no existan. La economía ambiental ha desarrollado y fundamentado métodos como el costo de viaje, la evaluación contingente y los precios hedónicos, entre otros, que permiten encontrar el valor económico de los servicios sociales, recreativos y ambientales que pueden proporcionar los espacios verdes. No es objetivo de este trabajo generar una discusión y análisis sobre esos métodos de evaluación económica y su aplicación en la toma de decisiones de la planificación urbana en la asignación de uso del suelo. Sin embargo, por su importancia se considera un área de discusión pendiente para urbanistas y economistas ambientales.

Por lo tanto, considerando los objetivos de este trabajo, es necesario destacar la importancia de sensibilizar, especialmente a los planificadores y administradores de parques, sobre las bondades de la participación ciudadana y de la incorporación de la demanda social de los citadinos en sus agendas de trabajo. En esta recomendación también hay que sugerir que los mismos administradores deben facilitar y promover en los centros de investigación de manejo de recursos naturales de sus ciudades, la investigación ecológica, social y económica de los parques. Los resultados y análisis de tales investigaciones permitirán a los pla- 
nificadores adecuar sus actuales programas de manejo y diseños arquitectónicos a la demanda social recreativa, desde una perspectiva de equidad y participación ciudadana.

En el enfoque de sustentabilidad actual, y considerando un esquema de manejo integral con perspectiva "paisajística," se puede concebir actualmente el parque urbano recreativo como un espacio público con usos potencialmente diversos, incluyente y sin discriminación.

\section{Conclusiones y recomendaciones}

La creación y el desarrollo histórico de diversos tipos de parques urbanos en diferentes ciudades del mundo ha respondido a metas sociales que privilegiaron inicialmente la inclusión de algunos grupos sociales, asignando en ocasiones actividades recreativas a priori. Esa visión de desarrollo del espacio verde trajo consigo la falta de consideración de algunos grupos sociales dentro de los espacios verdes, lo que resultó en discriminación y generación de conflictos sociales. Con la actual concepción de Parque Sustentable, la meta social de llevar salud integral humana y ecológica a todos los residentes citadinos, se puede lograr sólo si se acepta la diversidad en la demanda social recreativa de los grupos sociales beneficiarios. En un enfoque de sustentabilidad y equidad social no se puede hablar de espacios verdes incluyentes mientras exista una problemática de exclusión dentro del espacio. Por ello, se hace indispensable sugerir las siguientes acciones:

- Flexibilizar el concepto de recreación en parques públicos y no definirlo únicamente como un espacio de recreación familiar y con fines de educación ambiental y objetivos ecológicos.

- Conocer la demanda recreacional de los grupos sociales que hacen uso de las áreas verdes en las diferentes localidades urbanas.

- Considerar que el espacio verde es un agente dinámico, no neutro, ya que es definido por las diversas actividades que los usuarios realizan o desean realizar dentro de él.

- Considerar que el espacio y las facilidades recreativas se pueden y deben adecuar a los gustos, preferencias, necesidades y diferentes capacidades de los usuarios.

- Aceptar que existen riesgos potenciales de exclusión, si no se toma en cuenta a grupos vulnerables a los que tradicionalmente no se les ha reconocido su derecho de uso 
recreativo, como mujeres, etnias/razas, homosexuales y personas con discapacidades o necesidades especiales.

- Valorar las bondades de la participación ciudadana como un mecanismo que, aun con ciertos requerimientos y riesgos, pudiera facilitar el desarrollo consensado de programas de creación, desarrollo, manejo y asignación de usos diversos, como la recreación en espacios verdes.

En la práctica se podrían emplear algunas de las técnicas ya mencionadas o una combinación de ellas para conocer la demanda de bienes y servicios de áreas verdes por parte de los grupos sociales. Los resultados proporcionarían indicadores de demanda recreativa en espacios verdes, acuerdos de cooperación entre los grupos sociales y la creación de programas consensuados de manejo, administración y uso recreativo. Para lograr lo anterior, se requiere la participación de diferentes profesionistas en desarrollo urbano, como arquitectos, economistas, sociólogos, antropólogos y especialistas en forestería urbana que conformen equipos de investigación y trabajo multidisciplinarios.

Consecuentemente, la integración de las recomendaciones anteriores lleva a considerar como eje de la dotación del servicio verde a la demanda social. Por lo que esa demanda social, si se considera su potencial de múltiples usos debiera incluirse en un esquema de manejo integral con una perspectiva paisajística. Esa perspectiva, a su vez, debiera ejecutarse por medio del diseño y operación de un Sistema Integral de Espacios Verdes Citadinos que contenga esquemas de participación ciudadana. Por lo anterior, y tomando en cuenta la posibilidad de que un solo parque sea incapaz de proporcionar todos lo servicios y usos demandados, algunos parques pudieran estar mayormente enfocados a desempeñar una función recreativa de cierto tipo, mientras que otros tendrían alguna función alternativa, cubriéndose de esa forma la diversidad en gustos y preferencias de la gente y las funciones de utilidad que pudieran proporcionar los espacios verdes.

Todo eso repercutirá en la generación de nuevos planes de áreas verdes y de recreación en las ciudades dentro de programas integrales de servicios urbanos. Asimismo, esto permitiría asignar de manera eficiente zonas verdes en una ciudad de acuerdo con la óptica de sustentabilidad que especifica el tipo de Parque Sustentable definido por Cranz y Boland (2004). No es posible concebir el desarrollo urbano sujeto únicamente a proyectos políticos individuales de sólo un servicio y un espacio a corto plazo, sino como parte de planes integrales dinámicos de bienes 
y servicios a largo plazo con participación ciudadana y adecuada distribución espacial de los parques en el paisaje urbano.

\section{Bibliografía}

Aminzadeh, Behnaz y Dokhi Afshar (2004), "Urban Parks and Addiction", Journal of Urban Design, 9 (1): 73-87.

Amnistía Internacional (2001), Crímenes de odio, conspiración de silencio. Tortura y malos tratos basados en la identidad sexual, Amnistía Internacional, Madrid.

Bedimo-Rung, Ariane, Andrew Mowen y Deborah Cohen (2005), "The Significance of Parks to Physical Activity and Public Health", American Journal of Preventive Medicine, 28 (252): 159-168.

Berlant, Laurent y Michael Warner (2005), “Sexo en público”, en R. Mérida (ed.), Sexualidades transgresoras. Una antología de estudios queer, Icaria, Barcelona, pp. 229-257.

Bolund, Per y Sven Hunhammar (1999), "Ecosystem Services in Urban Areas", Ecological Economics, 29: 293-301.

Burgess, Jacquelin, Carolyn Harrison y Melanie Limb (1988), "People, Parks and the Urban Green: A Study of Popular Meanings and Values for Open Spaces in the City", Urban Studies, 25: 455-473.

Carta de la Habana (2001), II Congreso Iberoamericano de Parques y Jardines Públicos, Instituto de Planificación Física de la República de Cuba-Asociación Española de Parques y Jardines Públicos de España.

Centro de las Naciones Unidas para los Asentamientos Humanos (2005), Programa Hábitat, http://www.un.org/spanish/ ag/habitat/agenda_s.htm, el 1 de abril de 2005.

Chauncey, George (1994), Gay New York: Gender, Urban Culture, and the Making of the Gay Male World, 1890-1940, Basic Books, Nueva York. 
Chiesura, Anna (2004), "The Role of Urban Parks for the Sustainable City", Landscape and Urban Planning, 68: 129-138.

CMMD (Comisión Mundial del Medio Ambiente y del Desarrollo) (1988), Nuestro futuro común, Alianza, Madrid.

Cranz, Galen y Michael Boland (2004), "Defining the Sustainable Park: A Fifth Model for Urban Parks", Landscape Journal, 23: 102-120.

Dascal, Guillermo (1993), "Mantención de áreas verdes en zonas urbanas desfavorecidas; un asunto pendiente en la planificación urbana", Revista de Geografía Norte Grande, 20: 19-24.

Dascal, Guillermo (1994), "Los espacios verdes apropiados (EVAs). Una propuesta para mejorar las condiciones de vida en zonas urbanas desfavorecidas en Santiago, Chile", Revista de Geografía Norte Grande, 21: 7-12.

Dascal, Guillermo (1995), “La participación comunitaria: aspecto clave para la gestación de espacios verdes apropiados (EVAS) en sectores de pobreza urbana”, en Anales de la Sociedad Chilena de Ciencias Geográficas, Universidad Austral de Chile, pp. 30-36.

DeVos, Els (2005), "Public Parks in Ghent's City Life: From Expression to Emancipation?", European Planning Studies, 13 (7): 1035-1061.

Engels, Friedrich (1999), The Condition of the Working Class in England, ed. de David McLellan, Oxford University Press, Oxford y Nueva York.

Fernández Christlieb, Federico (2000), Europa y el urbanismo neoclásico en la Ciudad de México. Antecedentes y esplendores, Plaza y Valdés, México.

Fernow, Bernhard (1911), A Brief History of Forestry, University Press Toronto, Canadá.

Foucault, Michel (1984), "Des espaces autres", Architecture, Movement, Continuité, 5: 46-49. 
Gobster, Paul (1998), “Urban Parks as Green Walls or Green Magnets? Interracial Relations in Neighborhood Boundary Parks", Landscape and Urban Planning, 41: 43-55.

Jones, Robert (2002a), "Enticement: The Role of Community Involvement in the Management of Urban Parks", Managing Leisure, 7: 18-32.

Jones, Robert (2002b), "Partnerships in Action: Strategies for the Development of Voluntary Community Groups in Urban Parks", Leisure Studies, 21: 305-325.

Krenichyn, Kira (2004), "Women and Physical Activity in an Urban Park: Enrichment and Support through an ethic care", Journal of Enviromental Psychology, 24: 117-130.

Lamas, Marta (1998), “Contribuciones al análisis sobre género y desarrollo. La perspectiva de género", Red de Gestión de Recursos Naturales, 12: 5-14.

List Reyes, Mauricio (2001), "Al encuentro de la vida gay urbana”, Cuicuilco, 7 (22): 71-79.

Low, Setha, Dana Taplin y Suzanne Scheld (2005), Rethinking Urban Parks. Public Space and Cultural Diversity, The University of Texas Press, Austin.

Martin, Fran (2000), "From Citizenship to Queer Counterpublic: Reading Taipei's New Park”, Communal/Plural, 8 (1): 81-94.

Marne, Pauline (2001), "Whose Public Space was it Anyway? Class, Gender and Ethnicity in the Creation of the Sefton and Stanley Parks, Liverpool: 1858-1872", Social and Cultural Geography, 2 (4): 421-443.

Miller, Robert (1997), "Planeación del enverdecimiento urbano", en L. Krishnamurthy y J. Nascimento (eds.), Áreas verdes urbanas en Latinoamérica y el Caribe, Universidad Autónoma de Chapingo, México, pp. 83-108.

Nieto, Sacramento (ed.) (2000), "Filosofía e Historia”, en Enciclopedia Interactiva Monitor, Rezza Editores, España. 
Pacheco Vega, Raúl y Obdulia Vega López (2001), “Dos modalidades de participación ciudadana en política ambiental”, Economía, Sociedad y Territorio, 3 (9): 25-62.

Payne, Laura, Andrew Mowen y Elizabeth Orsega-Smith (2002), "An Examination of Park Preferences and Behaviors among Urban Residents: The Role of Residential Location, Race and Age”, Leisure Sciences, 24: 181-198.

Park, Deborah, John Radford y Michael Vickers (1998), "Disability Studies in Human Geography. Progress in Human Geography", Progress in human geography, 22 (2): 208-223.

Pérez Bertruy, Ramona (2003), "Políticas públicas y áreas verdes de la metrópolis mexicana 1772-1911, ponencia presentada en la XI Reunión de historiadores mexicanos, estadounidenses y canadienses. Las Instituciones en la Historia de México: formas, continuidades y cambios, Monterrey, México.

PNUMA (Programa de Naciones Unidas para el Medio Ambiente) (2003), Proyecto de Estadísticas e Indicadores Ambientales del Foro de Ministros de Medio Ambiente de América Latina y el Caribe, documento preparado para la XIV Reunión del Foro de Ministros de Medio Ambiente de América Latina y el Caribe, PNUMA, Panamá.

Podmore, Julie (2001), "Lesbians in the Crowd: Gender, Sexuality and Visibility along Montreal's Boul. St-Laurent", Gender, Place and Culture, 8 (4): 333-355.

Rishbeth, Clare (2001), "Ethnic Minority Groups and the Design of Public Open Space: An Inclusive Landscape", Landscape Research, 26 (4): 351-366.

Salcedo Hansen, Rodrigo (2002), "El espacio público en el debate actual: una reflexión crítica sobre el urbanismo postmoderno", EURE, 28 (84): 5-19.

Salvador Palomo, Pedro (2003) La planificación verde en las ciudades, Gustavo Gilli, Barcelona. 
Sánchez Domínguez, Arturo (2002), “De sanjuaneras y metreras, entornos públicos y placer homosexual", en Memoria Revista Mensual de Política y Cultura, 155, http:// memoria.com.mx/155/Sanchez.htm, 5 de julio de 2005 .

Sánchez Crispín, Álvaro y Álvaro López López (2000), "Visión geográfica de los lugares gay de la Ciudad de México", Cuicuilco, 7 (18): 1-16.

Sasidharan, Vinot, Fern Willis y Geoffrey Godbey (2005), "Cultural Differences in Urban Recreation Patterns: An Examination of Park Usage and Activity Participation across Six Population Subgroups”, Managing Leisure, 10: 19-38.

Secretaría de Desarrollo Social (2005), Primera Encuesta Nacional sobre Discriminación en México, Secretaría de Desarrollo Social Consejo Nacional para Prevenir la Discriminación, México.

Scott-Webber, Lennie y Anna Marshall-Baker (1998), “Two Contrasting Approaches to Urban Accessibility for Individuals with Disabilities or Special Needs", The Journal of Urban Technology, 5 (1): 1-15.

Sorensen, Mark, Valerie Barzetti, Kari Keipi y John Williams (1998), Manejo de las áreas verdes urbanas. Documento de buenas prácticas, División de Medio Ambiente, Banco Interamericano de Desarrollo, Washington, D.C.

Speller, Gerda y Neil Ravenscroft (2005), "Facilitating and Evaluating Public Participation in Urban Parks Management", Local Environment, 10 (1): 41-56.

Taylor, Dorceta (1999), “Central Park as Model for Social Control: Urban Parks, Social Class and Leisure Behavior in Nineteenth-century America", Journal of Leisure Research, 31 (4): 420-477.

“The Garden City Movement” (1906), The Lancet, 168 (4341): 1291-1292.

Yiftachel, Oren (1998), "Planning and Social Control: Exploring the Dark Side", Journal of Planning Literature, 12 (2): 395-406. 
Whitzman, Carolyn (2002), "Feminist Activism for Safer Social in High Park, Toronto: How Women got Lost in the Woods", Canadian Journal of Urban Research, 11 (2): 299-321.

Williams, Richard, Hans Vogelsong, Gary Green y Kari Cordell (2004), "Outdoor Recreation Participation of People with Mobility Disabilities: Selected Results of the National Survey of Recreation and the Environment", Journal of Park and Recreation Administration, 22 (2): 85-101.

Recibido: 4 de abril de 2006. Reenviado: 23 de junio de 2006. Reenviado: 2 de octubre de 2006. Aprobado: 4 de octubre de 2006.

Ramiro Flores-Xolocotzi es maestro en ciencias. Actualmente realiza estudios de doctorado en el posgrado Forestal del Colegio de Postgraduados, Campus Montecillo. Su línea de investigación se centra en la economía ambiental y recreación en espacios verdes urbanos. Entre sus publicaciones destacan: "Deforestation and Land Use Change in Mexico", Journal of Sustainable Forestry, 12 (1): 171-191, (2001, en coautoría con Juan Manuel Torres Rojo); "Cambio de uso del suelo entre los sectores forestal, agrícola y pecuario", Ciencia Forestal, 25 (87): 5-24 (2000, en coautoría con Juan Manuel Torres Rojo).

Manuel de Jesús González-Guillén es profesor-investigador en el Colegio de Postgraduados. Es doctor en economía de los recursos naturales y el ambiente, y en análisis de política. Entre sus publicaciones destacan: "Definición de áreas forestales con potencialidad recreativa", Agrociencia, 30, 1996: 129-138 (1996, en coautoría con J. René Valdez Lazalde y Cruz Velasco González); "Population and Land Use Change in the California Mojave: Natural Habitat Implications of Alternative Futures", Рориlation Research and Policy Review, 22: 373-397 (2003, en coautoría con Lori M. Hunter, Matt Stevenson, Kimberly S. Karish, Richard E. Toth, Thomas C. Edwards Jr., Robert J. Lilieholm y Mary Cablk); "Estimación de cobertura arbórea mediante imágenes satelitales multiespectrales de alta resolución”, Agrociencia, 40: 383-394 (2006, en coautoría con José René Valdez Lazalde y Héctor Manuel de los Santos Posadas), y "Sistema de información para administrar plantaciones comerciales en Méxi- 
co", Madera y Bosques, 12 (2): 77-90 (2006, en coautoría con Édgar A. Sánchez Moreno, David H. del Valle Paniagua y J. René Valdez Lazalde); Demanda, disponibilidad de pago y costo de oportunidad hídrica en la cuenca Tapalpa, Jalisco. Aceptado para su publicación en Madera y Bosques 13 (1), 2007, en coautoría con Christopher López Paniagua, J. René Valdez Lazalde y Héctor Manuel de los Santos Posadas. 